\title{
Personal Communication Habits Can Make Us Cynical About Politics
}

\author{
LIZZIE MARTIN | UNIVERSITY OF PENNSYLVANIA
}

W

e often perceive politicians as self-serving, preoccupied with accumulating and protecting power and money for themselves. These perceptions have significant effects: they can make us less interested in participating in politics, less conscientious about complying with policies, and less trusting of other people in general. They can make us cynical about civic engagement, and they can make us susceptible to conspiracy theories and negative campaign strategies.

These are big problems, and they are often understood by scholars to be caused by various political actors-mostly politicians and the media-themselves. However, Troels Bøggild, Lene Aarøe, and Michael Bang Petersen identify another cause: the way that we as individuals share news about politics with each other.

Many of us get news about politics from our family members, colleagues, and friends. Most of that news originates with media organizations or politicians, but the authors argue that as we pass it along, we decide what to emphasize based on a

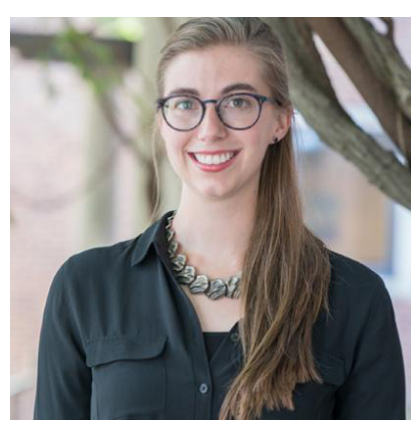
psychological bias that causes us to be particularly aware of things that violate our expectations. This tendency to expose and counteract self-interested behavior can be useful because it helps us support social cooperation. However, our tendency to emphasize violations of social norms can also contribute to low levels of trust in politicians.

Lizzie Martin is a joint PhD student in the Annenberg School for Communication and the Department of Political Science at the University of Pennsylvania. Her research interests center on US public opinion and foreign policy. Lizzie holds a Masters in Public Affairs and an $A B$ in public policy and creative writing from Princeton University. Through the Scholars in the Nation's Service Initiative, she also served as a graduate fellow at the US Department of State.

In the APSA Public Scholarship Program, graduate students in political science produce summaries of new research in the American Political Science Review. This piece, written by Lizzie Martin, covers the article by Troels Bøggild, Lene Aarøe, and Michael Bang Petersen, Aarhus University, "Citizens as Complicits: Distrust in Politicians and Biased Social Dissemination of Political Information." The full article is available at: https://doi.org/10.1017/S0003055420000805.
To identify the effects of personal communication on trust in politicians, the authors of this paper use experiments that resemble a game of "Telephone," in which players pass a whispered message along to their teammates, and the team that best preserves the original message wins. In these experiments, participants read a version of an article about politicians' actions. In one version, the politicians were described as self-serving, with an emphasis on the personal strategy driving their decisions. In another, the article focused on the issues instead. After reading one of the articles, each participant described the information in it to someone else, who then passed along the message to another participant. This allowed the authors to identify what information was lost and what information participants chose to emphasize, as well as how quickly the story changed.

In general, people passed along substantially more information from the article that emphasized politicians' self-interested actions than the one that emphasized issues. People also remembered more information about politicians' self-serving motivations than the issues involved. Perhaps most troublingly, exposure to stories about politicians' selfishness made participants significantly less trusting of politicians, their decisions, and Congress in general. Even those who only heard second-hand accounts became more cynical about politics.

The choices people made in these experiments suggest that even if stories about politicians shared by journalists or other public figures were completely balanced, common biases in the kinds of news we tend to pass along to one another would elevate stories about self-interested politicians. We tend to draw attention to behavior that violates norms we want to protect, and that attention can contribute to distrust in politicians and political processes.

This study is helpful in understanding the way that negative stories and conspiracy theories about politicians spread. It also suggests that feelings of distrust or cynicism that we might feel toward politicians aren't necessarily symptoms of disengagement from politics. Instead, they are a defense mechanism against self-serving actors. However, they can make us susceptible to manipulation. Given these findings, we might think more critically about the types of news we share with each other and work to broaden the information that informs our trust in political actors and processes, rather than relying on limited and often biased perceptions. 